\title{
Self-compassion and forgiveness: The protective approach against rejection sensitivity
}

Halis SAKIZ

The University of Manchester, UK halis.sakiz@postgrad.manchester.ac.uk

Hakan SARIÇAM

Dumlupinar University, Turkey hakansaricam@gmail.com

\begin{abstract}
The main purpose of this study was to examine the relationship between self-compassion, forgiveness and rejection sensitivity. Participants were 496 university students who completed the Self-compassion Scale, the Trait Forgiveness Scale and the Rejection Sensitivity Questionnaire. The data were analyzed with Pearson Moments Correlation Analysis and Multiple Regression Analysis (MRA). In findings, forgiveness and self-compassion were negatively related to rejection sensitivity, and forgiveness was also associated with self-compassion. Moreover, rejection sensitivity was predicted negatively by forgiveness and self-compassion, and also self-compassion is the best predictor for rejection sensitivity. The findings were discussed in light of the related literature.
\end{abstract}

Keywords: Self-compassion, forgiveness, rejection sensitivity, mediating

\section{Introduction}

Recently, there has been a trend in psychology which places high importance on the positive and developmental perspective towards the self (MacBeth \& Gumley, 2012). Self-compassion, a concept influenced by this trend, has attracted considerable interest among researchers who aimed to explore its nature and analyze its relationships with other psychological constructs (e.g., Breines \& Chen, 2012; Neff, 2003a; Neff, 2003b; Raes, 2010; Wei, Liao, Ku, \& Shaffer, 2011). Since its rise as a popular idea in contemporary psychology, a significant body of research has come up with findings showcasing that self-compassion is a useful coping strategy for a few reasons. Firstly, it can encourage constructive thinking and enhance positive emotions (Neff, Hsieh, \& Dejitterat, 2005). Secondly, it can predict positive mental health and adaptive psychological functioning (e.g., Neff, Rude, \& Kirkpatrick, 2007; Rendon, 2007; Yarnell \& Neff, 2013). Finally it can promote resilience in negative life experiences (Akin, 2010; Neff, 2003a; Neff \& McGehee, 2010).

For long years, enhancement of some self-view constructs such as self-esteem and self-care was thought to improve the healthy intra-individual attitudes and strengthen the functioning of individuals within the society (Neff, 2012). However, the challenge reached a peak when a series of research (e.g., Crocker \& Park, 2004; Freis, Brown, \& Arkin, 2015; Lee, 2014; Neff, 2011) came up with data documenting the negative consequences of making immoderate effort to enhance self-esteem and self-care; with frustration, aggression, narcissistic manners and bullying being some of these consequences. On the other hand, self-compassion started to receive greater attention as an alternative strategy for individuals' conception of their functional 
attitudes towards themselves because self-compassion was less associated with damaging outcomes and it could improve easier than self-esteem which was more resistant to change (Neff, 2011; Bosson \& Swan, 2009).

Self-compassion was defined as the ability to alternate negative attitudes towards the self with a sense of warmth, concern and care (Neff \& McGehee, 2009). According to Neff, and Dahm (2009) self-compassion includes three components interacting with each other. Firstly, selfkindness is the caring and understanding attitude towards the self which replaces a negative selfcritical view. Therefore, it displays a stance which is far from a self-judgmental way of thinking. The second component is a sense of common humanity which is defined as the ability to think that making a mistake is common to everybody and that blaming the self for any failure is not an appropriate way of compensation. The third component of self-compassion is mindfulness. Mindful people are usually aware of their experiences and admit them as they are. They are less likely to over-identify with these experiences and to attribute the negative feelings associated with them to the self.

Besides the evidence that indicates the relationship between self-compassion and adaptive psychological functioning, self-compassion has also been considered as a protective attitude against some tendencies which might cause negative outcomes for human well-being (Leary, Tate, Allen, Adams, \& Hancock, 2007; Raes, 2010). As one of these tendencies, rejection sensitivity was defined as "the disposition to defensively expect, readily perceive and intensely react to rejection" (Erozkan, 2009, p.3). Rejection sensitivity might evoke negative emotions when there is a rejection by a partner, when expectations are not met (Wang, McDonald, Rubin, \& Laursen, 2012), or when the individual is not liked, not appreciated or not included into a particular context (Erozkan, 2009).

A distinctive characteristic of people with high rejection sensitivity is that they have an expectation of rejection by significant others. Rejection-sensitive people might perceive insensitive and minor behaviors of others as rejection, and overreact to such situations in a way that this reaction undermines their relationships with people and decreases their feelings of wellbeing (Downey \& Feldman, 1996). Depending on the level of frustration, the resulting painful situations might include self-harming behaviors such as prolonged isolation or negative selfjudgment (McDonald, Bowker, Rubin, Laursen, \& Duchene, 2010).

The likelihood for young people to experience rejection in their relationships is more than that of people from other age groups (Wang et al., 2012) because rejection sensitivity is particularly marked in young ages when people engage in a variety of relationships (Downey \& Feldman, 1996). University students consist of mostly young people who constantly interact with their environments for various reasons. They might set close friendships, form romantic relationships and/or get acquainted with colleagues in educational settings. What is common about these relations is that young people might highly rely on them in terms of social, emotional and academic support (Ozen, Sumer, \& Demir, 2010). However, a possible frustration in these relationships might result in negative consequences (Bowker, Thomas, Norman, \& Spencer, 2011) when the sensitivity to rejection and reliance on these relationship is high.

Moreover, the prior studies marked that the correlations between rejection sensitivity and adaptive or maladaptive psychological functioning, it has also damaged some structures which might cause negative outcomes for human well-being (Ayduk et al., 2008; Ayduk, Downey, \& Kim, 2001; London, Downey, Bonica, \& Paltin, 2007). As one of these structures, forgiveness was defined as an individual's permission to reinstate trust in the relationship even though the person was subjected to hurtful behavior and the ability of both offending and offended individuals to discuss this hurtful behavior to improve their relationship (Hargrave \& Sells (1997). 
Forgiveness requires cognitive, emotional, and behavioral changes (Enright, Gassin, \& Wu, 1992). By leaving aside the fight with the person and incident that unjustly hurt herself, forgiveness is an individual's willingness to forego anger and their rights to judge the offending person and to act in the same way to that person. And at the same time, this is a process to try to feel feelings toward the offending person that they do not deserve such as compassion, generosity, and love, and is an unconditional present related to acceptance that offended person offers to the offending person (Enright \& Fitzgibbons, 2000). McCullough, Worthington, and Rachal (1997) stated that the basic motives underlying forgiveness were decreased revenge and decreased avoidance with increased benevolence and good will towards the person committed the offense (transgression). Even though forgiveness is not a motive itself, it is based on the change in the motives of revenge, avoidance from the offending person, and kindness toward that person that emerges when the individual is offended.

Forgiveness is individual's process of replacing feelings of revenge with feelings of tolerance and empathy in order to improve the damaged relationship. Forgiveness does not require the denial of past errors and covering of errors. The process forgiveness is neither the ignoring of unfairness nor transformation of justice into revenge (Rodden, 2003). In addition to these different opinions on what is forgiveness, it is noted that it is different than some other concepts and this discrimination should be done. In various studies, forgiveness has been found to increase hope and self-esteem by reducing anxiety and depression (Al-Mabuk, Enright, \& Cardis, 1995; Freedman \& Enright, 1996; Hebl \& Enright, 1993). Similarly, when compared with unforgiving individuals, forgiving individuals were found to have higher life satisfaction (Sastre, Vinsonneau, Neto, Girard, \& Mullet, 2003) and better well-being (Karremans, Van Lange, Ouwerkerk, \& Kluwer, 2003).

\subsection{The Current Study}

Considering the nature of self-compassion and forgiveness as positive attitudes towards the self or others and the potential benefit it might provide for overcoming the negative outcomes of rejection sensitivity, a relationship might be anticipated between these three constructs. Although past research examined the nature of these concepts separately and explored them in connection with some other constructs, the relationship between them has not been investigated before. Little research (Christman, 2012; Neff \& Beretvas, 2013) to date has examined the effects of self-compassion in the context of rejection sensitivity. On the other hand, if those with high rejection sensitivity are able to master the skills of self-compassion, they may be less likely to experience the multitude of negative interpersonal consequences that are associated with rejection sensitivity. This study is an attempt to expand the literature and knowledge of selfcompassion in the form of a rejection sensitivity. Rejection sensitivity has effective role on life satisfaction and it is negatively associated with life satisfaction (Ayduk, Downey, \& Kim, 2001). In contrast, self-compassion and forgiveness have positive relationship with life satisfaction (Allen, Goldwasser, \& Leary, 2012; Sastre et al., 2003). Although the relationships between rejection sensitivity and abnormal variables such as depression (Ehnvall et al., 2009), social anxiety (Fang et al., 2011), negative parents attitudes have been widely examined, much less research has focused on rejection sensitivity and its relationship with self-structures like self-compassion and positive concept such as forgiveness. Embarking on this literature gap, this study aims to analyze the relationships between these three concepts. We hypothesize that:

$\mathrm{H}_{1}$ : Self compassion is negatively associated with rejection sensitivity.

$\mathrm{H}_{2}$ : Self compassion is positively associated with forgiveness.

$\mathrm{H}_{3}$ : Forgiveness is negatively associated with rejection sensitivity. 


\section{Method}

\subsection{Participants}

The present research was carried out with a sample of 496 university students 254 (51.21\%) of whom were female and $242(48.79 \%)$ were male students from different grade levels enrolled in different departments of a mid-size state university in Turkey. Their ages ranged from 18 to 32 years $(M=21.86) .102$ students $(20.56 \%)$ were freshmen, $123(24.80 \%)$ were sophomores, 149 (30.04\%) were juniors and $122(24.60 \%)$ were senior students.

\subsection{Instruments}

\subsubsection{Self-Compassion Scale}

Self-compassion was measured by using Self-Compassion Scale (Neff, 2003b). Selfcompassion Scale is a 26-item self-report measurement consisting of six sub-scales which measure self-kindness, self-judgment, common humanity, isolation, mindfulness, and overidentification. Each item was rated on a 5-point Likert-type scale (1=strongly disagree to $5=$ strongly agree). Turkish adaptation of this scale was done by Deniz, Kesici, \& Sümer (2008). Cronbach $\alpha$ internal consistency coefficient was found as . 89. In the concurrent validity, significant relationships were found between the self-esteem $(r=.62)$, life satisfaction $(r=.45)$ and self-compassion. Test-retest reliability coefficient was .83 .

\subsubsection{Trait Forgiveness Scale (TFS)}

TFS was developed by Berry, Worthington, O'Connor, Parrott III, \& Wade (2004), and it consists of 10-items (e.g., "I can usually forgive and forget an insult") and one dimension. Each item was rated on a 5 -point Likert-type scale ( $1=$ strongly disagree to $5=$ strongly agree). Turkish adaptation of this scale was done by Sarıçam and Akın (2013). According to confirmatory factor analyses, 10 items yielded one factors as original form and that the one-dimensional model was well fit $\left(\chi^{2}=106.47, \mathrm{sd}=32, \mathrm{RMSEA}=.077, \mathrm{CFI}=.89, \mathrm{GFI}=.95, \mathrm{AGFI}=.91, \mathrm{SRMR}=.062\right)$. Factor loadings ranged from .52 to .77 . Cronbach $\alpha$ internal consistency coefficient was found as . 67. In the concurrent validity significant relationship $(r=.84)$ was found between the Trait Forgivingness Scale and The Heartland Forgiveness Scale. Test-retest reliability coefficient was .88. Corrected item-total correlations ranged from .37 to .48 .

\subsubsection{Rejection Sensitivity Questionnaire (RSQ)}

The RSQ, developed by Downey and Feldman (1996) and adapted for Turkish participants by Erozkan (2004; 2009), was used to determine the rejection sensitivity levels of students. This questionnaire consists of 18 items (e.g., "You ask someone you don't know well out on a date") with each describing hypothetical interpersonal situations in which respondents make requests of important others such as parent, teacher, friend, or romantic partner. Participants are required to rate their agreement with each item on a 6-point scale (1=very unconcerned, 6=very concerned; $1=$ very unlikely, 6=very likely). Principal components' analysis by Downey and Feldman led them to identify a one-factor solution that provided an adequate resolution of the item correlation matrix. They reported an internal consistency coefficient (Cronbach's $\alpha$ ) of .83, test-retest reliability coefficients of .83 and .78 for three-week and four-month retest intervals, respectively, and supportive construct validation evidence from three additional studies. The internal consistency coefficient (Cronbach's $\alpha$ ) of the RSQ was found to be .81 and the testretest reliability coefficient of the RSQ was calculated as .81 . The parallel form validity of the RSQ was tested with the Interpersonal Sensitivity Measure (Boyce \& Parker, 1989) and the correlation coefficient was found to be .64 (Erozkan, 2004).

\subsection{Data Analysis}

Permission for participation of students was obtained from related head of department. Researchers administered the self-report questionnaires to the students in the classroom 
environment; participants were all volunteer students, not from intact classes. The measures were counterbalanced in administration. Students did not place their names on the measures and were advised not to talk each other. Participants completed the questionnaires in approximately in $15 \mathrm{~min}$.

In this study, the analysis of the data was carried out using Pearson's correlation and stepwise regression method analysis. Before carrying out the analysis, normality, homogeneity, Mahalanobis distance values, singularity, tolerance, VIF, and Durbin-Watson hypothesis were controlled. For multiple regression analysis, rejection sensitivity was entered as dependent variable; self-compassion, and forgiveness were entered as independent variables. These analyses were carried out using package analysis programmer.

\section{Findings}

\subsection{Intercorrelations and Descriptive Data}

Pearson product moment correlation test was applied for finding correlation coefficients between variables and results was shown Table 1.

Table 1: Descriptive Statistics, Alphas, and Inter-correlations of the Variables

\begin{tabular}{lccc}
\hline Variable & $\mathbf{1}$ & $\mathbf{2}$ & $\mathbf{3}$ \\
\hline 1. Self-compassion & - & $.47^{* *}$ & $-.55^{* *}$ \\
2. Forgiveness & - & - & $-.45^{* *}$ \\
3. Rejection Sensitivity & & & - \\
$M$ & 81.64 & 37.22 & 45.50 \\
$S D$ & 17.28 & 7.72 & 16.47 \\
Alpha & .80 & .82 & .73 \\
\hline${ }^{*} p<.05, * * p<.01$ & & &
\end{tabular}

Table 1 shows the inter-correlations of the variables, means, standard deviations, and internal consistency coefficients of the variables used. When the table is examined, it is seen that there were significant correlations between self-compassion, forgiveness and rejection sensitivity. Self-compassion, $(r=-.55, \mathrm{p}<.01)$ and forgiveness $(r=-.45, \mathrm{p}<.01)$ related negatively to rejection sensitivity. Moreover, there is a positive significant correlation between selfcompassion and forgiveness $(r=.47, \mathrm{p}<.01)$

\subsection{Regression Analysis}

Before creating the regression analysis to be used in the current study, the relationships between all variables were taken into consideration. However; alternative models were tested with the related total points of three variables and the last finding which demonstrated the most excellent concinnity is described in Table 2 .

Table 2: Multiple linear regression analysis for rejection sensitivity

\begin{tabular}{lcccccccc}
\hline Variables & \multicolumn{2}{l}{$\begin{array}{c}\text { Unstandardized } \\
\text { Coefficients }\end{array}$} & $\begin{array}{c}\text { Standardized } \\
\text { Coefficients }\end{array}$ & & & & \\
& $\mathbf{B}$ & $\mathbf{S E}_{\mathbf{B}}$ & $\boldsymbol{\beta}$ & $\mathbf{t}$ & $\mathbf{R}$ & $\boldsymbol{R}^{2}$ & $\mathbf{F}$ \\
1. Self-compassion & -.53 & .04 & -.55 & $14.24^{*}$ & .55 & .30 & 202.80 \\
2. Self-compassion + & -.42 & .04 & -.44 & $10.29^{*}$ & & & \\
$\quad$ Forgiveness & -.51 & .09 & -.24 & $5.66^{*}$ & & .59 & 124.21 \\
& & & & & &
\end{tabular}

$* p<.001$

Dependent variable: Rejection sensitivity (RS)

Independent variable: Self compassion (SC), Forgiveness (F) 
As a result of the stepwise multiple regression analysis made, it is observed that the model is significant $\left(\mathrm{R}=.59, \mathrm{R}^{2}=.35, \mathrm{~F}=124.21, \mathrm{p}=0,000\right)$ and the independent variables entering the regression analysis explain $35 \%$ of the changes on the dependent variable. In that case, selfcompassion is the one of the best predictor for rejection sensitivity.

\section{Discussion}

The basic aim of this study was to investigate the relationship between self-compassion, forgiveness and rejection sensitivity. First, as hypothesized, self-compassion has negatively predicted to rejection sensitivity. Present research finding suggests that higher self-compassion is associated with lower rejection sensitivity. Although research in this subject is bounded, there is support that self-compassionate people function better in relationships than those low in selfcompassion. Baker and McNulty (2011) found that men high in self-compassion were more motivated to fix interpersonal mistakes, demonstrated increased problem solving behaviors, demonstrated accommodation, and reported fewer declines in relationship satisfaction over time, than men low in self-compassion. Christman (2012) claim that some of the negative consequences of rejection sensitivity, namely poor relationship satisfaction and increased levels of depression may depend on the level of self-compassion, such that with high levels of selfcompassion, there were no significant associations between rejection sensitivity and depression, and rejection sensitivity and relationship satisfaction. That is to say, there is no direct relationship between rejection sensitivity and self-compassion.

Second, as anticipated, self-compassion was positively related to forgiveness. Roxas, David, and Caligner (2014) suggested that compassion involves being touched by the suffering of others, opening one's awareness to others' pain and not avoiding or disconnecting from it, so that feelings of kindness toward others and the desire to alleviate their suffering emerge. On the other hands, Forgiveness can be characterized as: 1) a choice to reconcile, 2) an attitude about setting things right, 3) a compassionate way of communicating, 4) a specific action, and 5) an ongoing, lifelong process. Above all, forgiveness expresses kindness. Forgiveness is a way of letting go of pain. When we forgive others, we release the pain of anger and bitterness. Sarıçam and Biçer (2015) emphasized that self-compassion was significantly associated with forgiveness of others. Neff and Pommier (2013) indicate that forgiving others requires understanding the vast web of causes and conditions that lead people to act as they do. Namely, self-compassion is a deficient factor for forgiveness.

Third, as estimated, rejection sensitivity was negatively predicted by forgiveness. Gollwitzer, Süssenbach, and Hannuschke (2015) also denoted that social rejection cause unforgiveness. None of us is immune to hurt, humiliation, rejection and spiritual suffering. These are part of our normal interactions and relationships with people. Almost daily we will encounter some hurt, and sometimes we react to this. One of the most common forms of reaction is to take offence, to become bitter, and this may lead to unwillingness to forgive (McIntosh et al., 2008). Although rejection sensitivity is a trigger of depression, forgiveness has repressive characteristic against depression. Therefore, and consistent with the results of the present study, it appears that if individuals can enhance their forgiveness, they may increase their rejection sensitivity.

Forgiveness is characterized with positive attitudes of individuals towards themselves especially when they experience negative life events (Worthington, Witvliet, Pietrini, \& Miller, 2007) like self-compassion (Leary et al., 2007; Neff, 2003b; Thompson \& Waltz, 2008). Another feature of self-compassion is that people avoid harsh feelings and judgments about themselves and provide themselves with feelings of warmth, kindness and interconnectedness with the rest of humanity (Neff, 2003a). On the other hand, people who perceive that their relationships are ignored by others might feel rejected and react too strongly in this situation. At this point the prediction of a decrease in rejection sensitivity by the increase in domains of self-compassion 
and forgiveness suggest that self-compassion might facilitate a healthier psychological process at the time when rejection sensitivity results in negative outcomes (Ayduk, Gyurak, \& Luerssen, 2009; McCarty, Wander, \& McCauley, 2007) and poses threat to the well-being of the individual (Bowker et al., 2011). This benefit of self-compassion can particularly be illustrated in self-compassionate individuals' motivation to constructively revise and self-regulate their interpersonal relationships and learn from these experiences (Breines \& Chen, 2012). Similarly, forgiveness is a regulation mechanism of interpersonal relations and psychological well-being (Krause \& Ellison, 2003). This constructive process can replace a self-harming behavior which might stem from attributing the reasons for rejection to the self. In addition to all these, selfcompassion has strong sub-factors such as self-kindness, mindfulness, and common humanity. Therefore its mediator role between forgiveness and rejection sensitivity may be normal. For example, the relationship between rejection sensitivity and mindfulness suggests that mindfully thinking can be an appropriate way of protecting the self from such damaging reactions because mindfulness can help to create a balanced and self-understanding attitude towards the presentmoment experience. As a result, this attitude might lessen the negative self-criticism evoked by attributing the reasons for the rejection to the self (Jopling, 2003; Neff, 2003a). In addition, recent research has shown that rejection sensitivity can also lead to damaging outcomes due to the self-judging and self-critical attitudes it evokes (Ayduk, Downey, \& Kim, 2001; Pearson, Watkins, \& Mullan, 2011). With this in mind, it can be maintained that self-kind people are not only more likely to be forgiving (Gilbert \& Procter, 2006) but also to disengage in extreme selfjudging and self-critical behaviors because self-kindness can elevate feelings of selfunderstanding and alleviate self-blaming attitudes (Neff, 2003a). This might prompt constructive reflection upon problems experienced in interpersonal relationships. There has been research emphasizing isolation and loneliness as outcomes of rejection sensitivity (e.g., Downey \& Feldman, 1996; Sandstrom, Cillessen, \& Eisenhower, 2003), and unforgiving (Fitness, 2001; McCullough, Worthington, \& Rachal, 1997; Worthington et al., 2007).

\section{Conclusion}

This is the first study which examined the relationship between self-compassion, forgiveness, and rejection sensitivity. Past research established that self-compassion could be a way of enabling young people to hold feelings of suffering, promote resilience in the event of negative life experiences and foster positive thinking about the self (Akin, 2010; Ayduk et al., 2001; Lee \& Bang, 2010; Neff, 2003a; Neff \& McGehee, 2010; Orzech, Shapiro, Brown, \& McKay, 2009; Rimes \& Wingrove, 2011; Schroevers \& Brandsma, 2010). This potential of self-compassion was tested if it could be mediator role on relationship between forgiveness and rejection sensitivity. Findings revealed strong relationships between the three concepts. It is argued that self-compassion and forgiveness can be used as a way of combating the negative consequences of rejection sensitivity.

This study was undertaken among university students. The population of university students usually consists of individuals who are more likely to engage in a variety of relationships (Wang et al., 2012). However, these relationships might result in real or imagined rejection which can negatively influence university students' psychological functioning (Bowker et al., 2011). Findings of this study suggest that forgiveness and development of self-compassion can be useful for young people with high rejection sensitivity when they are encouraged to resist destructive self-critical tendencies, recognize the level of their interconnection with others, and deal with their emotions with greater clarity and equanimity (Neff, 2003a).

Consequently, we highlight that interventions such as cognitive and behavioral counseling programs can consider self-compassion as a means of self-regulation, psychological well-being, forgiveness and healthy social functioning. When they employ self-compassion as an approach and target young people who experience relationship problems, these interventions can help people to (a) enhance their levels of interpersonal achievement, (b) develop empathy skills to 
better understand others' perspectives, and (c) achieve a level of regarding others and themselves positively and unconditionally.

\section{Limitations}

We should note that there are some limitations in the current study. In this design it was not possible to examine the developmental changes in self-compassion. Longitudinal studies can be addressed in order to study the developmental trends regarding the impact of self-compassion and forgiveness on individuals with rejection sensitivity. Secondly, although the number of participants was acceptable, a larger sample might be more beneficial in detecting more reliable interactions between variables. In addition, the research context was particular to a sample from a single university site in Turkey and the entire sample included Turkish students with similar cultural orientations. Although self-compassion, forgiveness and rejection remain universal concepts, it should not be assumed that the same findings and patterns will apply to Western cultures or more diverse populations. More cross-cultural studies representing participants with more diverse orientations can be conducted in order to check the extent to which findings can be generalized across participants and studies.

\section{References}

Akın, A. (2010). Self-compassion and loneliness. International Online Journal of Educational Sciences, 2, 702-718.

Al-Mabuk, R.H., Enright, R.D., \& Cardis, P.A. (1995). Forgiveness education with parentally love-deprived late adolescents. Journal of Moral Education, 24, 427- 444.

Allen, A. B., Goldwasser, E. R., \& Leary, M. R. (2012). Self-compassion and well-being among older adults. Self and Identity, 11(4), 428-453

Ayduk, O., Downey, G., \& Kim, M. (2001). Rejection sensitivity and depressive symptoms in women. Personality and Social Psychology Bulletin, 27, 868-877.

Ayduk, O., Gyurak, A., \& Luerssen, A. (2009). Rejection sensitivity moderates the impact of rejection on self-concept clarity. Personality and Social Psychology Bulletin, 35, 14671478.

Ayduk, Ö., Zayas, V., Downey, G., Cole, A. B., Shoda, Y., \& Mischel, W. (2008). Rejection sensitivity and executive control: Joint predictors of borderline personality features. Journal of Research in Personality, 42, 151-168.

Baron , R. M., \& Kenny, D. A. (1986). Moderator-mediator variables distinction in social psychological research: conceptual, strategic, and statistical considerations. Journal of Personality and Social Psychology, 51(6), 1173-1182.

Baumeister, R. F., Bushman J., \& Campbell, W. K. (2000). Self-esteem, narcissism, and aggression: Does violence result from low self-esteem from threatened egotism? Current Directions in Psychological Science, 9, 26-29.

Bosson, J. K., \& Swan, W. B. (2009). Self-esteem. In Mark R. Leary, Rick H. Hoyle (Eds.) Handbook of Individual Differences in Social Behavior. New York: Guilford Press.

Bowker, J. C., Thomas, K. K., Norman, K. E., \& Spencer, S. V. (2011). Mutual best friendship involvement, best friends' rejection sensitivity, and psychological maladaptation. Journal of Youth and Adolescence, 40, 545-555.

Breines, J. G., \& Chen, S. (2012). Self-compassion increases self-improvement motivation. Personality and Social Psychology Bulletin, 38, 1133-1143.

Crocker, J., \& Park, L. E. (2004). The costly pursuit of self-esteem. Psychological Bulletin, 130, $392-414$.

Christman, J. A. (2012). Examining the interplay of rejection sensitivity, self-compassion, and communication in romantic relationships. (PhD diss.), University of Tennessee. 
Deniz, M. E., Kesici Ş., \& Sümer A. S. (2008). The validity and reliability study of the Turkish version of Self-compassion Scale. Social Behavior and Personality: An International Journal, 36(9), 1151-1160.

Downey, G., \& Feldman, S. (1996). Implications of rejection sensitivity for intimate relationships. Journal of Personality and Social Psychology, 70, 1327-1343.

Ehnvall, A., Mitchell, P. B., Hadzi-Pavlovic, D., Malhi, G. S., \& Parker, G. (2009). Pain during depression and relationship to rejection sensitivity. Acta Psychiatrica Scandinavica, $119,37-382$.

Enright, R. D., Gassin, E. A., \& Wu, C. (1992). Forgiveness: A developmental view. Journal of Moral Education, 21, 99-114

Erman, T. (2001). Rural migrants and patriarchy in Turkish cities. International Journal of Urban and Regional Research, 25, 118-133.

Erozkan, A. (2004). Rejection, vulnerability, cognitive appraisal and coping in romantic relationships (Unpublished doctoral dissertation). Karadeniz Technical University, Trabzon.

Erozkan, A. (2009). Rejection sensitivity levels with respect to attachment styles, gender, and parenting styles: A study with Turkish students. Social Behavior and Personality, 37, 114.

Fang, A., Asnaani, A., Gutner, C., Cook, C., Wilhelm, S., \& Hofmann, S. G. (2011). Rejection sensitivity mediates the relationship between social anxiety and body dysmorphic concerns. Journal of Anxiety Disorders, 25, 946-949.

Fitness, J. (2001). Betrayal, rejection, revenge, and forgiveness: An interpersonal script approach. In Leary, M. R. (Ed). Interpersonal Rejection. New York: Oxford University Press.

Freedman, S. R., \& Enright, R. D. (1996). Forgiveness as an intervention goal with incest survivors. Journal of Consulting and Clinical Psychology, 64, 983-992.

Freis, S. D., Brown, A. A., \& Arkin, R. M. (2015). Narcissisim and protection against social threat. In Patrick J. Carroll, Robert M. Arkin, Aaron L. Wichman (Eds) Handbook of Personal Security. New York, NY : Psychology Press

Gilbert, P., \& Procter, S. (2006). Compassionate mind training for people with high shame and self-criticism: overview and pilot study of a group therapy approach. Clinical Psychology and Psychotherapy, 13, 353-379.

Gollwitzer, M., Süssenbach, P. \& Hannuschke, M. (2015). Victimization experiences and the stabilization of victim sensitivity. Frontiers in Psychology, 6, 439. doi: 10.3389/fpsyg.2015.0043

Hargrave, T. D. \& Sells, J. N. (1997).The development of a forgiveness scale. Journal of Marital and Family Therapy, 23, 41-62.

Hebl, J. H., \& Enright, R. D. (1993). Forgiveness as a psychotherapeutic goal with elderly females. Psychotherapy, 30, 658-667.

Hu, L. T., \& Bentler, P. M. (1999). Cut off criteria for fit indexes in covariance structural analysis: Conventional criteria versus new alternatives. Structural Equation Modeling, $6,1-55$.

Jopling, D. A. (2000). Self-knowledge and the self. New York: Routledge.

Karremans, J. C., Van Lange, P. A. M., Ouwerkerk, J. W., \& Kluwer, E. S. (2003). When forgiveness enhances psychological well-being: The influence of interpersonal commitment. Journal of Personality and Social Psychology, 84, 1011-1026

Kenny, D. A., Korchmaros, J. D., \& Bolger, N. (2003). Lower level mediation in multilevel models. Psychological Methods, 8, 115-128.

Kocacik, F., Kutlar, A., \& Erselcan, F. (2007). Domestic violence against women: A field study in Turkey. The Social Science Journal, 44, 698-720. 
Krause, N., \& Ellison, J. G. (2003). Forgiveness by God, forgiveness of others, and psychological well-being in late life. Journal for the Scientific Study of Religion, 42(1), 77-93.

Leary, M. R., Tate, E. B., Allen, A. B., Adams, C. E., \& Hancock, J. (2007). Self-compassion and reactions to unpleasant self-relevant events: Implications of treating oneself kindly. Journal of Personality and Social Psychology, 92, 887-904.

Lee, E. J. (2014). The relationship between unstable self-esteem and aggression differences in reactive and proactive aggression. The Journal of Early Adolescence 34(8), 1075-1093.

Lee, W. K., \& Bang, H. J. (2010). The effects of mindfulness-based group intervention on the mental health of middle-aged Korean women in community. Stress and Health, 26, 341348.

Lockard, A. J., Hayes, J. A., Neff, K. D. \& Locke, B. D. (2014). Self-Compassion Among College Counseling Center Clients: An Examination of Clinical Norms and Group Differences. Journal of College Counseling, 17, 249-259.

London, B., Downey, G., Bonica, C., \& Paltin, I. (2007). Social causes and consequences of rejection sensitivity. Journal of Research on Adolescence, 17, 481-506.

MacBeth, A., \& Gumley, A. (2012). Exploring compassion: A meta-analysis of the association between self-compassion and psychopathology. Clinical Psychology Review, 32, 545552.

McCarty, C. A., Vander, A., \& McCauley, E. (2007). Cognitive features associated with depressive symptoms in adolescence: Directionality and specificity. Journal of Clinical Child \& Adolescent Psychology, 36, 147-158.

McCullough, M. E., Worthington, E. L., \& Rachal, K. C. (1997). Interpersonal forgiving in close relationships. Journal of Personality and Social Psychology, 73, 321-336

McDonald, K. L., Bowker, J. C., Rubin, K. H., Laursen, B., \& Duchene, M. S. (2010). Interactions between rejection sensitivity and supportive relationships in the prediction of adolescents' internalizing difficulties. Journal of Youth and Adolescence, 39, 563574.

McIntosh et al. (2008). Forgiving the Perpetrators of the September 11th Attacks: Associations with Coping, Distress, and Religiousness. In Forgiveness: A Sampling of Research Results. Washington, DC: APA Office of International Affairs.

Mikolajczyk, R. T., Brzoska, P., Maier, C., Ottova, V., Meier, S., Dudziak, U., ... El Ansari, W. (2008). Factors associated with self-rated health status in university students: a crosssectional study in three European countries. BMC Public Health, 8, 215-224.

Neff, K. D. (2003a). Development and validation of a scale to measure self-compassion. Self and Identity, 2, 223-250.

Neff, K. D. (2003b). Self-compassion: An alternative conceptualization of a healthy attitude toward oneself. Self and Identity, 2, 85-102.

Neff, K. D. (2004). Self-compassion and psychological well-being. Constructivism in the Human Sciences, 9, 27-37.

Neff, K. D., Hsieh, Y., \& Dejitterat, K. (2005). Self-compassion, achievement goals, and coping with academic failure. Self and Identity, 4, 263-287.

Neff, K. D., \& McGehee, P. (2009). Self-compassion and psychological resilience among adolescents and young adults. Self and Identity, 9, 225-240.

Neff, K. D., Rude, S. S., \& Kirkpatrick, K. L. (2006). An examination of self-compassion in relation to positive psychological functioning and personality traits. Journal of Research in Personality, 41, 908-916.

Neff, K. D., \& Dahm, K. A. (2009). Self-Compassion: What it is, what it does, and how it relates to mindfulness. To appear in in M. Robinson, B. Meier \& B. Ostafin (Eds.) Mindfulness and Self-Regulation. New York: Springer.

Neff, K. D. \& Vonk, R. (2009). Self-compassion versus global self-esteem: Two different ways of relating to oneself. Journal of Personality, 77, 23-50. 
Neff, K. D. (2011). Self-compassion, self-esteem, and well-being. Social and Personality Compass, 5, 1-12.

Neff, K. D. (2012). The science of self-compassion. In C. Germer \& R. Siegel (Eds.), Compassion and Wisdom in Psychotherapy, 79-92. New York: Guilford Press.

Neff, K. D., \& Pommier, E. (2013). The relationship between self-compassion and otherfocused concern among college undergraduates, community adults, and practicing meditators. Self and Identity, 12(2), 1-17.

Neff, K. D., \& Beretvas, S. N. (2013). The role of self-compassion in romantic relationships. Self and Identity, 12(1), 78-98.

Orzech, K. M., Shapiro, S. L., Brown, K. W., \& McKay, M. (2009). Intensive mindfulness training-related changes in cognitive and emotional experience. Journal of Positive Psychology, 4, 212-222.

Ozen, A., Sumer, N., \& Demir, M. (2011). Predicting friendship quality with rejection sensitivity and attachment security. Journal of Social and Personal Relationships, 28, 163-181.

Pearson, K. A., Watkins, E. R., \& Mullan, E. G. (2011). Behaviour Research and Therapy, 49, 597-605.

Raes, F. (2010). Rumination and worry as mediators of the relationship between selfcompassion and depression and anxiety. Personality and Individual Differences, 48, 757-761.

Rimes, K. A., \& Wingrove, J. (2011). Pilot study of mindfulness-based cognitive therapy for trainee clinical psychologists. Behavioural and Cognitive Psychotherapy, 39, 25-241.

Rodden, J. (2003). Forgiveness, education, public policy: The road not yet taken. Modern Age, Fall, 46(4), 333-341.

Roxas, M. M., David, A. P., \& Caligner, E. T. (2014). Examining the relation of compassion and forgiveness among Filipino counselors. Asian Journal of Social Sciences \& Humanities, 3(1), 53-62.

Rubin, K. H., Bukowski, W. M., \& Laursen, B. (2009). Handbook of peer interactions, relationships, and groups. New York, NY: Guilford Press.

Sandstrom, M. J., Cillessen, A. H. N., \& Eisenhower, A. (2003). Children's appraisal of peer rejection experiences: Impact on social and emotional adjustment. Social Development, $12,530-550$.

Sarıçam, H., \& Akın, A. (2013). Affedicilik Ölçeğinin Türkçe Formu: Geçerlik ve güvenirlik çalışması. Hasan Ali Yücel Ĕgitim Fakültesi Dergisi, 10(1), 37-46.

Sarıçam, H., \& Biçer, B. (2015). The predictive role of moral value and self-compassion on forgiveness. GEFAD / GUJGEF 35(1), 109-122.

Sastre, M. T. M., Vinsonneau, G., Neto, F., Girard, M., \& Mullet, E. (2003). Forgivingness and Satisfaction with Life. Journal of Happiness Studies, 4(3), 323-335.

Schroevers, M. J., \& Brandsma, R. (2010). Is learning mindfulness associated with improved affect after mindfulness-based cognitive therapy? British Journal of Psychology, 101, 95-107.

Shapiro, S. L., Brown, K. W., Thoresen, C., \& Plante, T. G. (2011). The moderation of mindfulness-based stress reduction effects by trait mindfulness: Results from a randomized controlled trial. Journal of Clinical Psychology, 67, 267-277.

Thompson, B. L., \& Waltz, J. (2008). Self-compassion and PTSD symptom severity. Journal of Traumatic Stress, 21, 556-558.

Wang, J., McDonald, K. L., Rubin, K. H., \& Laursen, B. (2012). Peer rejection as a social antecedent to rejection sensitivity in youth: The role of relational valuation. Personality and Individual Differences, 53, 939-942.

Wei, M., Liao, K. Y., Ku, T., \& Shaffer, P. A. (2011). Attachment, self-compassion, empathy, and subjective well-being among college students and community adults. Journal of Personality, 79, 191-221. 
Worthington, E. L., Witvliet, J. V. O., Pietrini, P., \& Miller, A. J. (2007). Forgiveness, health, and well-being: a review of evidence for emotional versus decisional forgiveness, dispositional forgivingness, and reduced unforgiveness. J Behav Med, 30, 291-302.

Yarnell, L. M., \& Kristin, D. N. (2013). Self-compassion, interpersonal conflict resolutions, and well-being. Self and Identity, 12, 146-159. 